\title{
STUDY OF CATALYTIC PROPERTIES OF SAPO-40
}

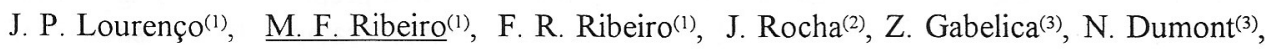 \\ E. G. Derouane ${ }^{(3)}$ \\ (1) Instituto Superior Técnico, Dep. Engenharia Química, 1096 Lisboa Codex, Portugal \\ (2) Universidade de Aveiro, Departamento de Química, 3800 Aveiro, Portugal \\ (3) Facultés Universitaires N. D. de la Paix, Laboratoire de Catalyse, B-5000 Namur, Belgium
}

A series of SAPO-40 samples with $\mathrm{Si}$ atomic fraction from 0.06 to 0.12 has been synthesised. The study of their catalytic properties has been evaluated by comparison with SAPO-37, USHY and mordenite, using as model reaction the cracking of n-heptane. The catalytic activity of SAPO-40 samples depends on the Si content, and is probably associated with the non-uniform distribution of silicon. SAPO-40 showed a stronger acidity than SAPO37 with a similar Si content. SAPO-40 is more resistant to deactivation by coke than the studied mordenite sample. Its selectivity for cracking products is comparable to USHY, but hydrogen transfer is lower for SAPO-40 than for USHY and mordenite.

\section{INTRODUCTION}

Silicoaluminophosphates (SAPO-n), the new generation of microporous molecular sieves that have been discovered [1], show interesting properties of potential use in adsorptive, ion exchange and catalytic applications [2,3]. In general these materials can be classified as mildly acidic, substantially more active than the aluminophosphates but generally less active than their zeolite analogues [4]. With medium pore species, the generally mild acidity combined with unique shape selectivity has resulted in improved catalytic selectivity in several reactions, namely for oligomerization of light olefins to gasoline-range products [3], alkylation and isomerization reactions [5].

In some structures the acidity can be varied by controlling synthesis conditions or by special pretreatment $[6,7]$. The main parameter that affects the protonic character is the environment of $\mathrm{Si}$ and $\mathrm{Al}$ atoms. Si may be present in two structurally different configurations, namely homogeneously distributed among the $\mathrm{Al}$ and $\mathrm{P}$ atoms, or forming $\mathrm{Si}$ islands $[7,8]$.

SAPO-40 was synthesised for the first time in 1984 [1], but only recently was obtained in a pure form [9]. It has the AFR topology [10] and consists on a large pore structure with a twodimensional system of channels, namely: 12-rings forming channels parallel to the c-axis and 8ring channels parallel to the b-axis. These channels, with free diameters of 6.7 and $3.8 \AA$, respectively, intersect to form a two dimensional system. The third direction is blocked by a wall of 4- and 6-rings perpendicular to the a-axis [9].

The properties of SAPO-40 are poorly characterized. In this paper we compare the catalytic properties of SAPO-40 with those of other large pores molecular sieves, such as SAPO-37, USHY and mordenite. 


\section{EXPERIMENTAL}

\subsection{Synthesis}

A series of SAPO-40 samples with increasing Si contents was synthesised according to the method recently described by N. Dumont et al. [9]. SAPO-37 was prepared according to Lok et al. [1]. The samples were prepared using pseudobhoemite (catapal B) as source of aluminium, fumed silica (aerosil 200, SERVA) as source of silicon, ortho-phosphoric acid ( $85 \%$, Merck) as source of phosphorus, tetrapropylammonium hydroxide as templating agent for the SAPO-40 and a mixture of both tetrapropylammonium and tetramethylammonium hydroxides for SAPO-37.

\subsection{Characterization}

The structure type and crystallinity of all the samples were checked by X-ray powder diffraction analysis on a Rigaku diffractometer using $\mathrm{CuK} \alpha$ radiation. The distribution of the elements in the framework was analysed by ${ }^{31} \mathrm{P},{ }^{27} \mathrm{Al}$ and ${ }^{29} \mathrm{Si}$ MAS NMR on a Brucker MSL 400 instrument and the crystal morphology was analysed by Scanning Electron Microscopy on a Phillips XL 20 instrument. The composition of unit cell was determined by EPMA (electron probe microanalysis) coupled to the microscope.

\subsection{Catalytic tests}

Two zeolite samples and one SAPO-37 sample were used as reference materials for comparison of catalytic properties; USHY (LZY 82 from UOP) with $\mathrm{Si} / \mathrm{Al}=4.5$, mordenite from $\mathrm{TOSOH}$ Corporation, with $\mathrm{Si} / \mathrm{Al}=5$ and $\mathrm{SAPO}-37$ with the composition $\left(\mathrm{Si}_{0.10} \mathrm{Al}_{0.50} \mathrm{P}_{0.40}\right) \mathrm{O}_{2}$.

Before the catalytic tests, the samples of SAPO-40 and SAPO-37 were calcined (in situ) to remove the template, by raising the temperature at a rate of $5^{\circ} \mathrm{C} / \mathrm{min}$ under nitrogen flow, from 20 to $550{ }^{\circ} \mathrm{C}$ and maintained at that temperature for 8 hours under a dry air flow. The temperature was then decreased under nitrogen flow to the reaction temperature.

The catalytic tests were carried out using n-heptane in a fixed bed reactor, at $350{ }^{\circ} \mathrm{C}, 1 \mathrm{bar}$ and molar ratio $\mathrm{HC} / \mathrm{N}_{2}$ of 0.14 . The products were analysed by gas chromatography.

The coke contents were determined by thermogravimetry on a Setaram TGA 92 micro balance.

\section{RESULTS AND DISCUSSION}

\subsection{Synthesis and characterization}

The SAPO-40 samples prepared and used in this work, appear to be pure in terms of structure type and presence of amorphous phase. Table 1 gives the product compositions as determined by EPMA. The $\mathrm{Na}$ content of the products is probably due to the presence of impurities in the reactants 
Table 1- Chemical composition of SAPO-40 samples

\begin{tabular}{l||c}
\hline Reference & Composition \\
\hline $\mathrm{S}-40(0.06)$ & $\mathrm{Na}_{0.03}\left(\mathrm{Si}_{0.06} \mathrm{Al}_{0.49} \mathrm{P}_{0.45}\right) \mathrm{O}_{2}$ \\
$\mathrm{~S}-40(0.07)$ & $\mathrm{Na}_{0.005}\left(\mathrm{Si}_{0.07} \mathrm{Al}_{0.49} \mathrm{P}_{0.44}\right) \mathrm{O}_{2}$ \\
$\mathrm{~S}-40(0.08)$ & $\left(\mathrm{Si}_{0.08} \mathrm{Al}_{0.48} \mathrm{P}_{0.44}\right) \mathrm{O}_{2}$ \\
$\mathrm{~S}-40(0.12)$ & $\mathrm{Na}_{0.016}\left(\mathrm{Si}_{0.12} \mathrm{Al}_{0.48} \mathrm{P}_{0.40}\right) \mathrm{O}_{2}$ \\
\hline
\end{tabular}

The ${ }^{29} \mathrm{Si}$ NMR spectrum (fig. 1 ) indicates a heterogeneous distribution of silicon in the framework for all the samples. The spectrum displays several resonances given by distinct and specific $\mathrm{Si}(\mathrm{nAl})$ configurations. The peak around $-89 \mathrm{ppm}$ is commonly assigned to $\mathrm{Si}(4 \mathrm{Al})$ configurations in the SAPO-region. The other signals are currently observed on other Si-rich SAPO's, such as SAPO-37 and SAPO-5, but there are some discrepancies in the literature on the specific assignment of these signals. In the faujasite structure type SAPO-37, P. Man et al. [11] found that the signals due to $\mathrm{Si}(\mathrm{nAl})(\mathrm{n} \leq 4)$ configuration appear at the same chemical shift as the other configurations in the silicoaluminate faujasite. For that reason it is difficult to assign the signals to a specific configuration in the framework on SAPO's with a heterogeneous distribution because the existence of silicoaluminate domains and/or silicon islands yields various Si configurations that appear at the same chemical shift. In this work, we can only state that the Si distribution in the various SAPO-40 samples is not homogeneous, and that the intensity of the lines characterizing $\mathrm{Si}(\mathrm{nAl})$ configurations in $\mathrm{Si}$ domains or in aluminosilicate islands (peaks lower than $-89 \mathrm{ppm}$ ) increases with the silicon content.

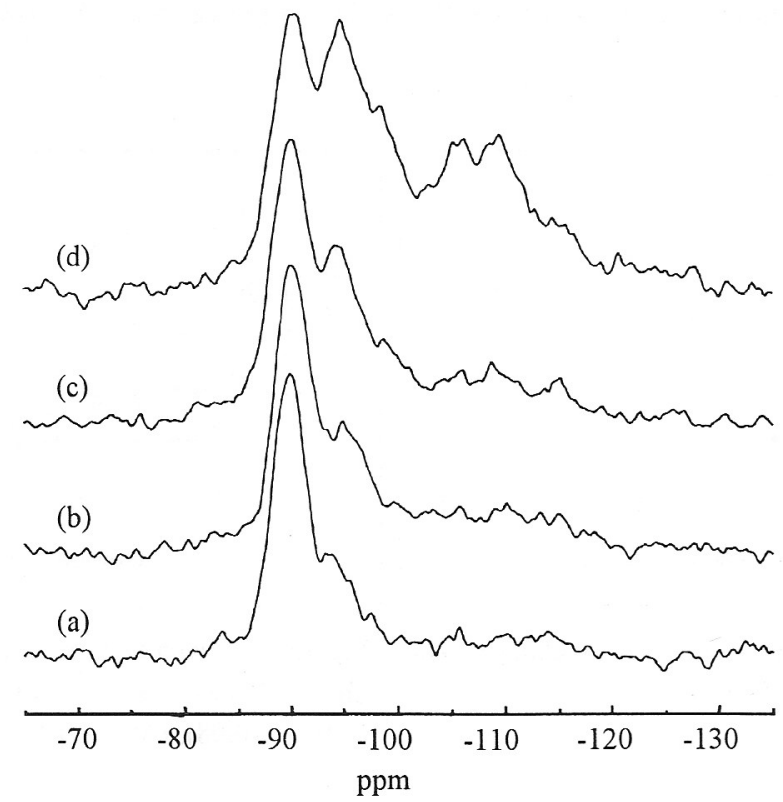

Figure 1 - ${ }^{29}$ Si NMR spectra of: (a) S-40 (0.06); (b) S-40 (0.07); (c) S-40 (0.08); (d) S-40 (0.12) 


\subsection{Catalytic Tests}

With the purpose to start a systematic study of catalytic properties of SAPO-40, we have chosen the cracking of n-heptane, a model reaction recommended to obtain information on the acidic activity of zeolite catalysts [12].

Due to the deactivation of the catalysts that occurs under these experimental conditions, we have compared the performances of the various samples for the same time on stream (initial, 6 and 60 minutes). The initial activity was estimated by the corrected exponential model [13].

Figures 2 (a) and (b) show the variation of n-heptane cracking activities for SAPO-40 samples as a function of their Si content and with time-on-stream. The initial activity increases with the silicon content on SAPO-40 samples. After 60 min of time on stream, the activities are the same for all samples, which means that the deactivation rate is the highest for the sample S-40(0.12). In a first approach, we could assume that the activity of the sample with $8 \%$ of Si should be slightly higher than that of the sample with $7 \%$ of $\mathrm{Si}$, but if we compare the amount of protons, we verify that $S-40(0.07)$ and $S-40(0.08)$ have respectively $0.045 \mathrm{H}^{+} / \mathrm{T}$ and $0.04 \mathrm{H}^{+} / \mathrm{T}$, which means that the influence of the protonic amount must also be considered.

As expected $[6,14]$, both the silicon content and its distribution in the framework play an important role in the catalytic activity of SAPO-40. ${ }^{29} \mathrm{Si}$ NMR data have suggested that all the samples display a heterogeneous distribution of Si. Comparison of the spectra of S-40(0.08) and $\mathrm{S}-40(0.12)$, shows that the latter sample contains more $\mathrm{Si}$ which does not belong to SAPO domain. On the other hand, the S-40(0.12) sample is much more active than the S-40(0.08) sample. Therefore, the observed increase of activity appears to be mainly influenced by the generation of specific Si environments between the different domains, which are on one side the aluminosilicate phase or the Si islands, and on the other side the SAPO domain. This point is now being developed by characterizing the acidity of the various SAPO-40 samples by FTIR spectroscopy [15].

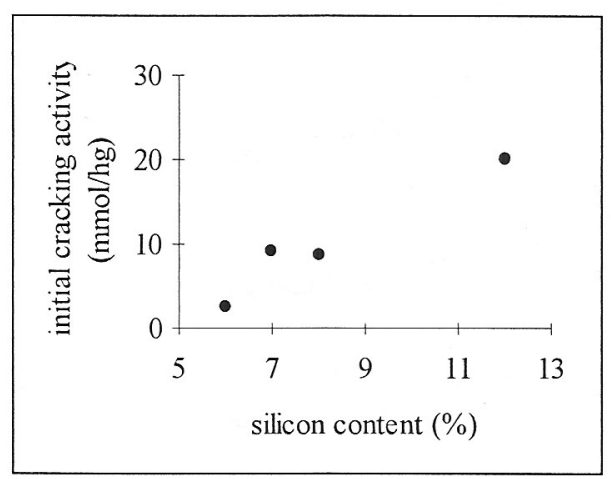

Figure 2a. Evolution of initial cracking activity with the content in silicon.

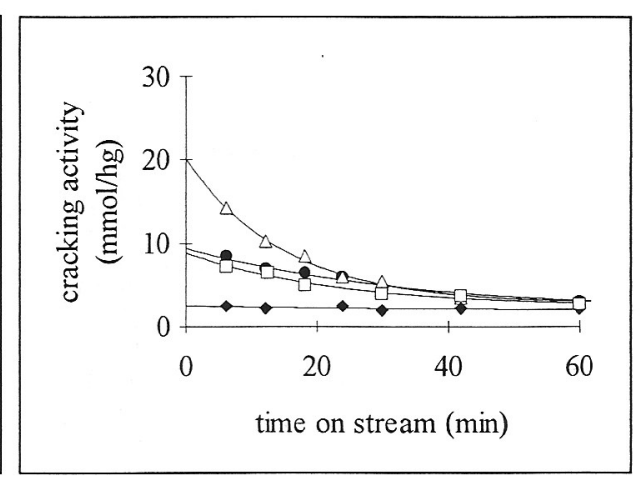

Figure $2 \mathrm{~b}$. Evolution of cracking activity with time on stream: $(\bullet)$ S-40 (0.06), (•)S-40 (0.07), (口)S-40 (0.08), ( $\triangle$ S) S-40 (0.12). 
An alternative way of studying the catalytic properties of SAPO-40 is by comparison with reference materials, whose catalytic properties are well known. Figure 3 compares the activities of cracking of n-heptane of USHY, mordenite, SAPO-37 and SAPO-40

SAPO-40 (Si-0.12) is more active for the cracking of n-heptane than SAPO-37 (Si-0.10), that shows, in these conditions, practically negligible activity. Zeolite USHY and mordenite are initially more active than SAPO-40 and much more so than SAPO-37 but after 6 minutes on stream, the activity of mordenite is already lower than that of $\mathrm{S}-40(0.12)$. The deactivation rate on mordenite is greater than on SAPO-40.

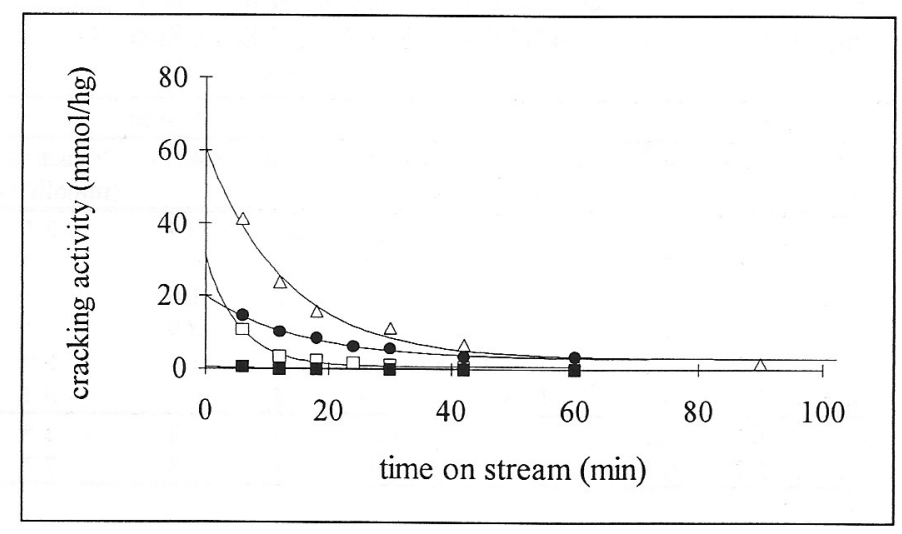

Figure 3. Evolution of the cracking activity with time on stream: USHY $(\Delta), \mathrm{S}-40(\mathrm{Si}-0.12)(\bullet)$,

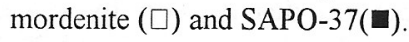

From these results we can conclude that the strength of the acid sites on SAPO-40 is greater than on SAPO-37. In SAPO-37(Si-0.10), silicon is homogeneously distributed [16] while on SAPO-40 the Si distribution is always heterogeneous, even for low Si contents. According to the results found for other SAPO's [16,17], the strength of acid sites at the border of the Si-islands is higher than that of isolated $\mathrm{Si}$ atoms. This is the main reason that can explain the activity differences between SAPO-40 and SAPO-37 with comparable silicon content.

Under the current experimental conditions, i.e. at a temperature of $350^{\circ} \mathrm{C}$, the initial conversion obtained on SAPO-37 was lower than $1 \%$, and it was impossible to compare selectivities with the other materials. Therefore, two runs were made at $450^{\circ} \mathrm{C}$, in order to compare selectivities of SAPO-40 and SAPO-37. Table 2 gives the product distribution for the solids tested at $350^{\circ} \mathrm{C}$ (SAPO-40, USHY and mordenite) and at $450^{\circ} \mathrm{C}$ (SAPO-37 and S-40(Si-0.07)).

Analysing selectivities of cracking products, and more precisely, the $\mathrm{C} 4 / \mathrm{C} 3$ ratio and iso/n (branched/ non branched products) at $\mathrm{t}=6 \mathrm{~min}$ (table 2), we can see that SAPO-40 shows typical values comparable to those reported for the $\mathrm{Y}$ zeolite. For the most siliceous samples, the $\mathrm{C} 4 / \mathrm{C} 3$ ratio greater than one, indicates the occurrence of side reactions besides the simple $\beta$-scission, and consequently an asymmetrical distribution, which is characteristic of $Y$ zeolite. 
High iso/n ratios are characteristic of strong acid sites, and small iso/n ratios are expected for materials with reduced channel aperture. According to the observed values, we can assume that SAPO-40 probably involves strong acid sites. Mordenite shows iso/n ratio lower than SAPO-40. From published structural data [9], it appears that the structure of SAPO-40 resembles to some extent the mordenite structure. However, after this preliminary study and mainly from the differences observed on iso/n ratios, we conclude that the SAPO-40 structure involves fewer constraints than the studied mordenite sample.

Table 2 - Products distribution observed during cracking of n-heptane at $\mathrm{T}=350^{\circ} \mathrm{C}$ for SAPO40 , USHY and mordenite and at $\mathrm{T}=450^{\circ} \mathrm{C}$ for SAPO-37 and $\mathrm{S}-40(\mathrm{Si}-0.07)$

\begin{tabular}{|c|c|c|c|c|c|c|c|c|c|}
\hline \multicolumn{5}{|c|}{$\mathrm{t}=6 \mathrm{~min}$} & \multicolumn{5}{|c|}{$\mathrm{t}=60 \mathrm{~min}$} \\
\hline Sample & $\mathrm{C} 3=/ \mathrm{C} 3$ & iso/n & $\mathrm{C} 4 / \mathrm{C} 3$ & $\begin{array}{c}\text { Crack. act } \\
\left(\mathrm{mmolh}^{-1} \mathrm{~g}^{-1}\right)\end{array}$ & $\mathrm{C} 3=/ \mathrm{C} 3$ & iso/n & $\mathrm{C} 4 / \mathrm{C} 3$ & $\begin{array}{l}\text { Crack. act. } \\
\left(\mathrm{mmolh}^{-1} \mathrm{~g}^{-1}\right)\end{array}$ & $\begin{array}{l}\text { Coke } \\
(\%)\end{array}$ \\
\hline S-40 (0.06) & 2.1 & 6.5 & 0.9 & 2.4 & 2.0 & 5.8 & 0.9 & 2.1 & 0.6 \\
\hline S-40 (0.07) & 1.3 & 6.5 & 1.0 & 8.5 & 1.5 & 3.5 & 0.7 & 2.8 & 1.8 \\
\hline $\mathrm{S}-40(0.08)$ & 1.0 & 7.0 & 1.2 & 7.2 & 1.8 & 1.2 & 1.6 & 1.2 & 1.1 \\
\hline S-40 (0.12) & 0.7 & 5.6 & 1.3 & 14.4 & 1.2 & 3.9 & 0.9 & 3.1 & 6.0 \\
\hline USHY & 0.2 & 6.3 & 1.2 & 41.5 & 1.0 & 5.8 & 1.1 & 2.9 & 6.9 \\
\hline Mordenite & 0.2 & 1.8 & 0.7 & 10.8 & 1.9 & 0.9 & 0.8 & 0.2 & 4.7 \\
\hline$S-37(0.10)^{(a)}$ & 4.0 & 1.7 & 0.8 & 2.5 & 4.2 & 2.3 & 0.8 & 1.5 & 2.3 \\
\hline S-40(0.07) (a) & 2.2 & 2.3 & 0.8 & 9.0 & 1.9 & 2.4 & 0.8 & 7.2 & 0.8 \\
\hline
\end{tabular}

(a) Runs carried out at $\mathrm{T}=450^{\circ} \mathrm{C}$

The above results are confirmed by differences on deactivation by coke. S-40(0.12) presents, at the end of the run, a larger coke content $(6 \%)$ than mordenite $(4.7 \%)$, but data in figure 3 suggest that the deactivation rate is much stronger for mordenite than for $S-40(0.12)$. This fact can indicate that the diffusional limitations provoked by coke deposition are less severe on SAPO-40 than on mordenite. It is important to emphasize that these conclusions are valid for this particular sample of mordenite, which may not be perfectly representative of the mordenite molecular sieve. On the other hand, if we compare the reduction of the iso/n ratio that occurs after 60 min of time on stream, for SAPO-40 samples and USHY, we conclude that for SAPO-40 the blockage of the porosity due to the coke deposition becomes an important factor for the reduction of branched products

The $\mathrm{C}_{4} / \mathrm{C}_{3}$ ratio, which may express the influence on catalysis of the field gradient in the pores or cages [18], the higher values of $\mathrm{C} 4 / \mathrm{C} 3$ ratio obtained on SAPO-40 and USHY are in agreement with a heterogeneous field related to a random distribution of charges in the framework due to the existence of Si-islands in SAPO-40.

Finally, if we analyse the olefin/paraffin selectivity which is illustrated by the propene/propane ratio, we observe that for SAPO-40 this ratio decreases as the silicon content increases, which means that hydrogen transfer reactions are favoured in the case of the most siliceous samples, for which the densities of acid sites are larger, thus hydrogen transfer reactions are likely to involve two neighbouring sites. On the other hand, the values of this ratio are much higher in SAPO-40 than in USHY or Mordenite, which means that SAPO-40 does not promote hydrogen transfer reactions efficiently. However, the highest value of the $\mathrm{C}_{3}=/ \mathrm{C}_{3}$ ratio was observed for SAPO-37 sample. The weak hydrogen transfer for SAPO-37 
was already demonstrated by other authors $[19,20]$ who have related this occurrence with the less polar character of SAPO-37 with respect to USHY. Rabo [3] concludes that the lack of hydrogen transfer generally observed in some medium pore SAPO's is suggestive of a mild acidity. It means that this result also indicates the weakest acidity of SAPO-37 sample as compared with SAPO-40

\section{CONCLUSION}

The preliminary results obtained in the present work indicate that SAPO-40 displays acidic catalytic properties which depend on the Si content and on the non homogeneous distribution of $\mathrm{Si}$ in the framework. Although the catalytic behaviour of SAPO-40 appears to be promising, furthers studies on catalysis and detailed characterization of the structure and acidity of SAPO40 are necessary. This work is now in progress.

\section{ACKNOWLEDGEMENTS}

This work was partially supported by JNICT under research contract STRDA /C/CTM/602/92

Financial support by "Project Science 12/M/90" for acquisition of RXD apparatus is gratefully acknowledged

We thank IMAT/Aveiro for access to the solid-state NMR facility.

\section{REFERENCES}

1. B.M. Lok, C.A. Messina, R.L. Patton, R.T. Gajek, T.R. Cannan and E.M. Flanigen, U.S.Patent $N^{\circ} 4,440,871$ (1984).

2. E.M. Flanigen, B.M. Lok, R.L. Patton and S.T. Wilson in Y. Murakami, A. Iigima, J.W. Ward (Eds), New Developments in Zeolite Science and Technology, Studies in Surface Science and Catalysis, vol 28, Elsevier, Amsterdam, 1986, p. 103.

3. J.A. Rabo, in E. Derouane, F. Lemos, C. Nacache and F.R. Ribeiro (Eds), Zeolite Microporous Solids: Synthesis, Structure and Reactivity, NATO ASI Series C n 352 Kluwer, Dordrecht, 1992, p. 531

4. B.M. Lok, C.A. Messina, R.L. Patton, R.T. Gajek, T.R. Cannan and E.M. Flanigen, J. Am. Chem. Soc. 106 (1984) 6093.

5. L. Yang, Y. Aizhen and Q. Xu, Appl. Catal., 67 (1991) 169.

6. M. Briend, M. Derewinski, A. Lamy and D. Barthomeuf in L. Guczi, F. Solymosi and P. Tétényi (Eds), New Frontiers in Catalysis, Studies in Surface Science and Catalalysis, vol 75 A, Elsevier, Amsterdam, 1993, p. 409.

7. M. Mertens, J.A. Martens, P.J. Grobet and P.A. Jacobs in D. Barthomeuf, E.G. Derouane and W. Hoelderich (Eds), Guidelines for Mastering the Properties of Molecular Sieves, NATO ASI Series B nº 221, Plenum, New York, 1990, p. 1.

8. L. Maistriau. N. Dumont, J.B. Nagy, Z. Gabelica and E.G. Derouane, Zeolites, 10 (1990) 243. 
9. N. Dumont, Z. Gabelica, E.G. Derouane and L.B. McCusker, Microporous Mater.,1 (1993) 149.

10. W.M. Meier and D.H. Olson, Atlas of Zeolite Structure Types, Butterworth-Heinemann, London, 1992, p. 30.

11. P.P. Man, M. Briend, M.J. Peltre, A. Lamy, P. Beaunier and D. Barthomeuf, Zeolites, 11 (1991) 563

12. G. Bourdillon, C. Guegen and M. Guisnet, Appl. Catal., 61 (1990) 123.

13. F. Lemos, J.M. Lopes and F.R. Ribeiro, J. Mol. Catal., 53 (1989) 265.

14. J.A. Martens, P.J. Grobet and P.A. Jacobs, J. Catal.,126 (1990) 229.

15. B. Onida, E. Garrone, J.P. Lourenço, M.F. Ribeiro and Z. Gabelica, in preparation.

16. J.A. Martens, C. Janssens, P.J. Grobet, H.K. Beyer and P.A. Jacobs, in P.A. Jacobs and R.A. van Santen (Eds), Zeolites: Facts, Figures, Future, Studies in Surface Science and Catalysis, vol 49 A, Elsevier, Amsterdam, 1988, p. 215.

17. B. Su and D. Barthomeuf, J. Catal., 139 (1993) 81.

18. C. Mirodatos and D. Barthomeuf, J. Catal., 93 (1985) 246.

19. A. Corma, V. Fornés, M.J. Franco, F.A. Mocholí and J. Pérez-Pariente in M. Occelli (Ed), Fluid Catalytic Cracking II: Concepts in Catalyst Design, ACS Symposium Series No 452 , 1991, p. 79.

20. J.M. Lopes, F. Lemos, F.R. Ribeiro, and E.G. Derouane, in P.A. Jacobs, N. I. Jaeger, L. Kubelková and B. Wichterlová (Eds), Zeolite Chemistry and Catalysis, Studies in Surface Science and Catalysis, vol 69, Elsevier, Amsterdam, 1991, p. 365. 